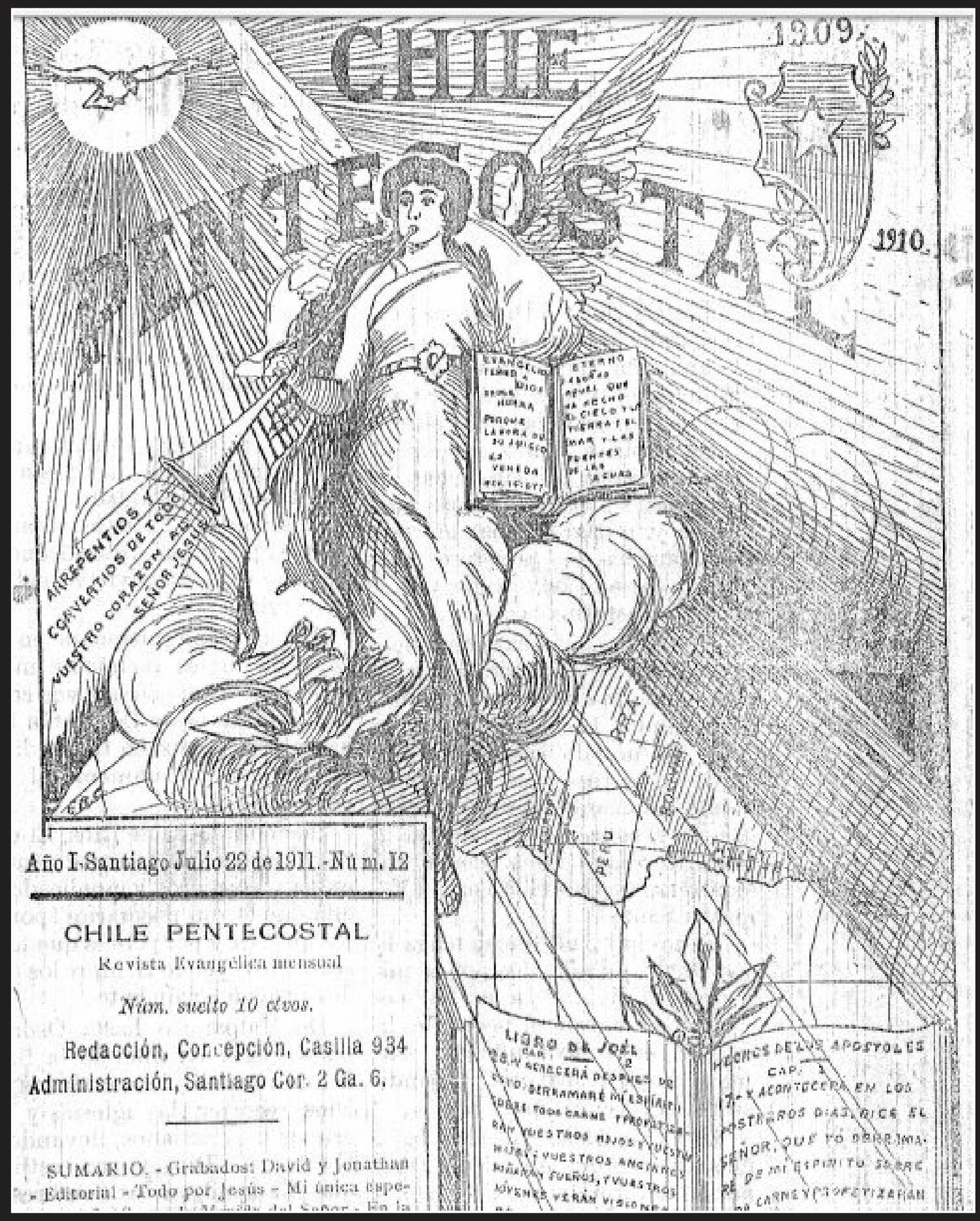




\section{Memoria de un olvido. La exclusión de mujeres de la memoria fundacional del pentecostalismo chileno (1909-1915)}

Memory of an omission. The exclusion of women from the founding memory of Chilean Pentecostalism (1909-1915) Memória de um esquecimento. A exclusão de mulheres da memória fundacional do pentecostalismo chileno (1909-1915)

\author{
Miguel Ángel Mansilla \\ Instituto de Estudios Internacionales (INTE), \\ Universidad Arturo Prat (Iquique, Chile) \\ mansilla.miguel@gmail.com \\ Wilson Enrique Muñoz Henríquez \\ Universidad de Tarapacá (Arica, Chile); Grup \\ d'Investigacions en Sociología de la Religió de \\ la Universidad Autónoma de Barcelona (Bar- \\ celona, España); Laboratoire d'Anthropologie \\ Sociale del Collège de France/CNRS/EHESS \\ (París, Francia) \\ wilsonocio@gmail.com
}

doi:10.11144/Javeriana.mys22-44.moem

\section{Resumen}

Las reconstrucciones que la historia apologética pentecostal, la teología y las ciencias sociales han realizado sobre los orígenes del pentecostalismo chileno, se caracterizan por una limitación significativa: la elaboración de una imagen negativa o el olvido de las mujeres de su memoria fundacional. El objetivo de este artículo es describir y analizar este fenómeno. A partir del análisis de fuentes primarias y secundarias, mostraremos que este olvido y difamación de la imagen femenina no se debe solo a una limitación metodológico-epistemológica, sino que obedece a una estrategia de poder liderada por pastores posicionados en los centros hegemónicos del pentecostalismo chileno.

\section{Palabras clave}

memoria; exclusión; poder; mujeres; pentecostalismo; Chile

\section{Abstract}

The reconstructions on the origins of Chilean Pentecostalism delivered by the Pentecostal apologetics, theology and social sciences are characterized by a significant limitation: the construction of a negative image or the exclusion of women in the movement's foundational memory. This article aims to describe and analyze this phenomenon. Based on the analysis of primary and secondary sources, it will be shown that the exclusion and the defamation of the female image is not only due to a methodological and epistemological limitation, but also to a power strategy lead by pastors positioned in the hegemonic centers of Chilean Pentecostalism.

\section{Carlos Daniel Piñones Rivera}

Instituto de Estudios Internacionales (INTE), Universidad Arturo Prat (Iquique, Chile)

carpinon@unap.cl

Artículo de investigación. Los autores agradecen el apoyo de la Vicerrectoría de Investigaciones, Innovación y Postgrado (VRIIP) de la Universidad Arturo Prat por su permanente apoyo en la ejecución de este artículo. El segundo autor agradece también al programa Becas Chile - doctorado de CONICYT.

\section{Resumo}

As reconstruções que a história apologética pentecostal, a teologia e as ciências sociais realizaram sobre os origens do pentecostalismo chileno, caracterizam-se por una limitação significativa: a elaboração de uma imagem negativa ou o esquecimento das mulheres de sua memória fundacional. $\mathrm{O}$ objetivo deste artigo é descrever e analisar tal fenómeno. A partir da análise de fontes primárias e secundarias, mostrar-se-á que o esquecimento e difamação da imagem feminina não se deve apenas a uma limitação metodológica-epistemológica, senão que obedece a uma estratégia de poder liderada por pastores posicionados nos centros hegemónicos do pentecostalismo chileno.

\section{Keywords}

memory; exclusion; power; women; Pentecostalism; Chile

\section{Palavras-chave}

memória; exclusão; poder; mulheres; pentecostalismo; Chile

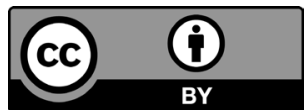

/ Mem.soc / Bogotá (Colombia) / ISSN 0122-5197 (impreso) - ISSN 2248-6992 (en línea) / 22 (44): 102-117 / enero-junio de 2018103 


\section{Introducción}

En los inicios del pentecostalismo chileno (1909) encontramos a dos personajes claves: Willis Hoover y Nellie Laidlaw (más conocida como Elena). Mientras que en torno a Hoover se erigió una leyenda dorada que nada logra opacar, pese a los relatos que ensombrecen su aura; ${ }^{1}$ sobre Elena se esculpió una leyenda negra que la transformó en una auténtica antiheroína, que luego fue arrojada al olvido, tanto de las memorias institucionales del pentecostalismo como de las investigaciones realizadas al respecto.

En la bibliografía apologética de las denominaciones pentecostales, las figuras de Elena y de otras mujeres están normalmente ausentes o son difamadas, en tanto que a Hoover se le asigna todo el liderazgo y fundación del movimiento. ${ }^{2}$ Por un lado, los pocos escritos que aluden a Elena ${ }^{3}$ solo la mencionan brevemente $\mathrm{y}$ omiten a las otras mujeres que jugaron un importante rol en los orígenes del movimiento. Por otro lado, aquellos que le han brindado un espacio mayor a esta líder femenina, la presentan como una mujer infame, vinculada al consumo de alcohol, la morfina y la prostitución, tachándola incluso de esquizofrénica y engañadora. ${ }^{4}$ Así, se ha construido una batería de estigmas como estrategia para no reconocerla y borrar su nombre de la memoria institucional y de los mitos fundacionales del pentecostalismo. Esta estrategia no resulta menor, pues olvidando a Elena y negando su rol como líder fundacional, se excluye también a las otras

1 Una presumible inclinación homosexual de la cual lo acusaron fue utilizada para sacarlo de su posición de superintendente de la Iglesia Metodista Pentecostal. Véanse Alice Rasmussen Schick y Dean Helland Talbert, La Iglesia Metodista Pentecostal, ayer y hoy, tomo II (Santiago: Plan Mundial de Asistencia Misionera en Chile, 1987) y Juan Kessler, A study of the older Protestant missions and churches in Perú and Chile. With special reference to the problems of division, nationalism and native ministry (Goes: Oosterbaan \& le Cointre N.V., 1967), 303-307.

2 Mario Hoover, El movimiento Pentecostal en Chile del siglo XX (Santiago: Eben Ezer, 2002); Rasmussen y Helland, La Iglesia Metodista, 41, 47-49.

3 Dorothy Bullon, Hacia una teología de Avivamiento (Barcelona: CLIE, 1998); Juan Sepúlveda, De peregrinos a ciudadanos. Breve historia del cristianismo evangélico en Chile (Santiago: Fundación Konrad Adenauer, 1999); Hoover, El movimiento Pentecostal.

4 Kessler, A study; Bullon, Hacia una teología. mujeres del liderazgo institucional, desvaneciendo así sus identidades y papel dentro de la historia.

Por su parte, los investigadores que han escrito sobre la historia del pentecostalismo chileno en general afirman y reafirman que Hoover fue el único líder fundacional, olvidando a Elena y a las otras mujeres como cofundadoras y líderes del movimiento. $\mathrm{Ni}$ siquiera las investigaciones históricas especializadas en los movimientos carismáticos y pentecostales las mencionan. ${ }^{5}$ En el ámbito de la teología existen algunas referencias que intentan redimirla del olvido, como es el caso de Elizabeth Salazar, la única investigadora que destaca a Elena como la principal líder del movimiento pentecostal que se estaba gestando y la presencia de otras mujeres cofundadoras. ${ }^{6}$ Sin embargo, pese a su aguda visión, la teóloga no logra desarrollar ni argumentar las razones de la exclusión de estas mujeres del mito fundacional y de las memorias escritas. En el ámbito de las ciencias sociales, los trabajos de Mansilla y Orellana ${ }^{7}$ destacan que si bien las mujeres son recordadas desde la ambigüedad y reciben metafóricamente el mismo estatus que los hombres, en realidad su liderazgo es negado como tal; además, señalan que este proceso de memoria/olvido del liderazgo femenino no es algo exclusivo del pentecostalismo y que está presente en diversos movimientos revivalistas. Pese a sus aportes al respecto, solo analizan el rol de las esposas de los pastores, excluyendo la figura de Elena y de otras mujeres que participaron en la fundación del pentecostalismo. ¿Por qué tanto las investigaciones como las denominaciones pentecostales han excluido, difamado, negado o ignorado el rol

5 Stanley Burgess y Eduard Van der Mass, Intenational Dictionary of Pentecostal Charismatic Movements (Michigan: Zondervan, 2003).

6 Elizabeth Salazar, «Todas seríamos rainhas. Historia do pentecostalismo chileno na perspectiva da mulher 1909-1935» (Dissertação de Maestrado em Ciencias da Religiao, UMESP, 1995).

7 Miguel Ángel Mansilla y Luis Orellana Urtubia, «Haciendo memoria de líderes religiosas olvidadas: el reconocimiento póstumo del trabajo de las pastoras en el pentecostalismo chileno», Sociedad y religión 23, n. ${ }^{\circ} 40$ (2013): 77-130; Miguel Ángel Mansilla y Luis Orellana, «Las pastoras pentecostales: metáforas sobre el liderazgo femenino en la Iglesia Evangélica Pentecostal (1972-2001)», Memoria y Sociedad, n. ${ }^{\circ} 36$ (2014): 83-98. 
de las mujeres dentro de la memoria fundacional del movimiento? Con el fin de responder esta pregunta y de superar las limitaciones antes planteadas, nos proponemos como objetivo describir y analizar los factores que influyeron en la exclusión y olvido de las mujeres de la memoria fundacional del pentecostalismo. Nuestra hipótesis de trabajo es doble. En primer lugar, sostenemos que parte de esta problemática se debe a la existencia de un prejuicio metodológico que ha desembocado en un reduccionismo epistémico-teórico. En general, las investigaciones realizadas sobre esta temática se han construido a partir de las fuentes oficiales de las denominaciones, dejando de lado fuentes previas a la institucionalización del pentecostalismo, como la revista Chile Evangélico, publicación independiente vinculada al líder presbiterano Tulio Morán, quien fue un claro defensor del naciente movimiento pentecostal y, sobre todo, de Elena. En esta revista encontramos tanto referencias apologéticas a Elena, como también testimonios sobre el desprestigio y deslegitimación de su liderazgo religioso. Si bien es importante reconocer que una vez que el movimiento pentecostal logró transformarse en iglesia (1910), la revista cambió de nombre a Chile Pentecostal y eliminó toda referencia a Elena; también lo es señalar que dio amplia cobertura a otras mujeres que fueron líderes y difusoras del movimiento pentecostal.

En segundo lugar, consideramos que la exclusión y difamación de las mujeres dentro de la memoria fundacional del movimiento es una estrategia de poder asociada al uso patriarcal de la memoria pentecostal. No se trata solo de un olvido, como han sostenido otros autores al referirse a la exclusión de la mujer de los mitos fundacionales de los movimientos pentecostales y carismáticos de América Latina. ${ }^{8}$ Se trata más bien de la elaboración de una memoria colectiva, entendiendo que esta última «no es

8 Mónica Tarducci, «Estudios feministas de religión: una mirada muy parcial», Cuadernos Pagu Universidad de Campinas, n. ${ }^{\circ} 6$ (2005): 97-114; Mansilla y Orellana, «Las pastoras pentecostales...». sólo una conquista, sino también, un instrumento y una mirada de poder». ${ }^{9}$

En esta línea hemos identificado tres tipos de memorias presentes en el pentecostalismo: una memoria negra referida a las fundadoras (especialmente a Elena), una memoria gris que alude a las mujeres líderes y otras mujeres que participaron en el movimiento, pero nunca muy resaltadas, y una memoria áurea alusiva a los hombres fundadores que suele engrandecerlos. En el primer caso se trata de crear y recrear una historia negra en torno a sus fundadoras para sacarlas del juego del poder. ${ }^{10}$ Estas mujeres se constituyen en personajes infames y oscuros que, al confrontar el poder, pasan a formar parte de una historia desgraciada. ${ }^{11}$ Así, ennegrecer la memoria de una fundadora es una construcción legítima para excluirla del mito fundacional, por lo tanto, ya no se ve como un problema institucional o individual: el problema es la mujer. En el segundo caso, construir una memoria gris de las mujeres líderes alude al acto de exponerlas limitadamente, vigilándolas y silenciándolas de manera constante, con el fin de generar una especie de olvido o silencio en torno a sus imágenes y roles. Estas estrategias presentes en la historia denominacional pentecostal revelarían aquello que Le Goff llamó «los mecanismos de manipulación de la memoria colectiva». ${ }^{12}$ En tercer lugar, encontramos la memoria áurea, una memoria prosopopeya, según la expresión de Candau, ${ }^{13}$ referida a esa especie de dioses, de buenos muertos, creadores ex nibilo del pentecostalismo, sin cuya presencia no habría existido el movimiento: los líderes hombres.

Para alcanzar nuestro objetivo y corroborar nuestra hipótesis, metodológicamente realizamos un análisis de fuentes documentales. Estas fuentes casi no han sido utilizadas

9 Jacques Le Goff, Enciclopédia Einaudi. Vol. I, Memória e História (Madrid: Imprenta Nacional - Casa da Moneda, 1991), 28.

10 Gedeón Freire, Matriz Pentecostal Brasileira. Asambleias de Deus. 1911-2011 (Río de Janeiro: Diálogos, 2013).

11 Michel Foucault, La vida de los hombres infames (La Plata: Altamira, 1996).

12 Le Goff, Enciclopédia Einaudi, 135.

13 Joel Candau, Memoria e identidad (Buenos Aires: Ediciones del Sol, 2001), 140

Memoria de un olvido / Miguel Ángel Mansilla, Wilson Enrique Muñoz Henríquez, Carlos Daniel Piñones Rivera / 105 
para abordar el problema enunciado, lo cual nos permitirá sortear el prejuicio metodológico planteado en nuestra primera hipótesis. En concreto, revisamos las revistas Chile Evangélico, Chile Pentecostal y Fuego de Pentecostés, utilizando la técnica de análisis de discurso.

El artículo está estructurado de la siguiente manera: (i) primero mostramos la exclusión, olvido y estigmatización que sufrió Elena Laidlaw, la líder más significativa del naciente movimiento pentecostal (memoria negra); (ii) posteriormente abordamos las actividades y el olvido que sufrieron otras líderes y mujeres que también estuvieron involucradas en la fundación del movimiento (memoria gris); (iii) luego describimos cómo se construyó el rol subalterno de la mujer y algunas de las estrategias de vigilancia masculina; (iv) después destacamos algunos casos puntuales que apoyaron el liderazgo incipiente de estas mujeres. Por último, esbozamos algunas consideraciones finales sobre nuestro caso de estudio.

\section{Una memoria negra. Elena Laidlaw y la exclusión del liderazgo femenino}

La memoria de Elena ${ }^{14}$ quedó marcada por el olvido de Hoover y otros líderes del pentecostalismo chileno, quienes no se interesaron en registrar y conservar sus aportes a la fundación del movimiento. Así lo ejemplifica una declaración fundacionalista del movimiento realizada en 1928 por nueve pastores, entre los que se reconoce a Willis Hoover y Víctor Pavez como los únicos fundadores del pentecostalismo, y se borra de un plumazo a Elena, así como también a otros y otras líderes del movimiento. ${ }^{15}$ Según Lavabre, los ejercicios de selectividad de la memoria colectiva se caracterizan por la capacidad que poseen de «ordenar el sentido del pasado en función de las representaciones, visiones del mundo, símbolos o "nociones" que permiten a los grupos sociales pensar el

14 No podemos extendernos aquí en la biografía de Elena. Para ello recomendamos ver Mansilla y Orellana, «Las pastoras pentecostales...».

15 Fuego de Pentecostés [Santiago], n. ${ }^{\circ}$ 54, mayo de 1933, 1. presente». ${ }^{16}$ En este juego de reordenamiento del pasado, el pentecostalismo desterró a las mujeres de su mito fundacional, mutilando así la posibilidad de repensarse como un movimiento creado por féminas.

De igual forma, muchos investigadores y especialistas del pentecostalismo han reproducido esta actitud institucional sobre los orígenes del movimiento, de modo que escasean las indagaciones sobre lo no dicho y lo no escrito. Consideramos que retomar esta dimensión de lo no dicho y lo no escrito, permite plantear una pregunta básica bajo una nueva luz: ¿Por qué una vez que se auto-organiza el movimiento pentecostal, Elena dejó de existir como una líder, tornándose invisible e innombrable?

Inicialmente se podría decir que fue Hoover quien excluyó a Elena como líder y luego como feligresa, pues «a final de ese año (1909) Hoover finalmente repudió a Nellie», ${ }^{17}$ con lo cual pasó, posteriormente, al olvido, al tiempo que fue borrada del mito fundacional pentecostal. De igual forma, Bristol, el obispo metodista episcopal, destaca que «Elena fue repudiada por Hoover y por los otros que la consideraban profetiza». ${ }^{18}$ Sabemos que una vez que el movimiento pentecostal se difundió y alcanzó autonomía, Hoover le quitó su respaldo a Elena. Finalmente, «después de los acontecimientos de 1909 y su gira por el sur de Chile en 1909-1910, [Elena] fue discontinuada como miembro en plena comunión de la Iglesia Metodista Episcopal, el 30 de abril de 1910». ${ }^{19}$ Una vez que Hoover tomó el liderazgo y la dirección del movimiento pentecostal, no solo excluyó a Elena del mismo, sino que también fue reduciendo el rol de la mujer hasta su más mínima expresión, para evitar que emergieran otras líderes que socavaran la autoridad masculina. Así, sobre cualquier mujer que quisiera seguir la senda revolucionaria e influyente iluminada por Elena, caerían las imprecaciones que la aplacaron a ella, así como un castigo ejemplar.

\footnotetext{
16 Marie Claire Lavabre, «Sociología de la memoria y acontecimientos traumáticos», en Guerra civil. Mito y memoria, ed. Julio Aróstegui y François Godicheau (Madrid: Marcial Pons, 2006).

17 Kessler, A study, 121.

18 Hoover, El movimiento Pentecostal, 163.

19 Florrie Snow, conversación personal, Santiago de Chile, 23 de
} marzo de 2014 
De esta manera se estableció un claro «patrón de liderazgo: los hermanos tenían que obedecer a los pastores». ${ }^{20}$ Este fuerte y autoritario liderazgo masculino implantado por Hoover «creó la tendencia de un culto a la personalidad pastoral», ${ }^{21}$ que eliminó, incluso, la posibilidad de que la esposa del pastor fuera llamada pastora, como se acostumbraba dentro del protestantismo. ${ }^{22}$

Pero esta exclusión no puede ser leída como un simple ataque personal encabezado por Hoover, pues se trató de un acto realizado en consonancia con el parecer de otros líderes pentecostales: los mismos que antes la consideraban como un instrumento privilegiado del Espíritu Santo, ahora la veían como una mujer extremadamente peligrosa. Incluso Víctor Paves, «quien fue despedido de su posición como ayudante de pastor de la Iglesia Metodista Episcopal y también de la casa pastoral que ocupaba, porque había apoyado a la hermana Elena», ${ }^{23}$ le dio la espalda. Muchos de sus seguidores, disidentes del movimiento metodista, también la atacaron, pese a que algunos habían estado dispuestos a ir a la cárcel con ella cuando la policía la detuvo debido a los supuestos altercados que generó en la iglesia metodista. ${ }^{24}$ De hecho, algunas mujeres (profetisas) que pertenecían al naciente movimiento, muchas de ellas esposas de pastores, hicieron eco, igualmente, de este rechazo y omisión. En síntesis, Elena entró en conflicto con el proceso de institucionalización del pentecostalismo, pues encarnaba la desestabilización (crisis) y era la cara visible del temor a perder el control del carisma que legitimaba a los nuevos líderes.

Pero Elena no fue arrojada totalmente al olvido, pues en la memoria pentecostal se retuvo y

20 Bullon, Hacia una teología, 66.

21 Bullon, Hacia una teología, 68.

22 Ignacio Vergara, El Protestantismo en Chile (Santiago: Ed. del Pacífico, 1962); Rasmussen y Helland, La Iglesia Metodista.

23 Hoover, El movimiento Pentecostal, 167.

24 «Tras ella iban todos sus partidarios dispuestos a quedarse detenidos en la policía; lo que el Prefecto no permitió, pero insistieron $y$ al fin se les permitió que queden algunas mujeres para acompañarla, la noche la pasaron orando y cantando gozosas de que fueran presas por la causa del Señor». Arturo Oyarzún, Reminiscencia histórica de la Obra Evangélica en Chile (Valdivia: Imprenta Alianza, 1921), 51. reconstruyó una imagen infame suya con la finalidad de excluir el liderazgo femenino del mito fundacional pentecostal. Los pentecostales utilizaron a Elena para promover el pentecostalismo entre las iglesias protestantes, pero una vez que lo lograron, su figura no fue útil y se generó una memoria negra en torno a ella. Como han señalado algunos autores, al observar fenómenos como estos vemos que no se trata solo de simples huellas que el pasado ha dejado en el presente, pues normalmente se han producido para ser transmitidas a generaciones sucesivas. ${ }^{25}$ Pero gracias a este mismo registro de olvido y difamación, «podemos regocijarnos como si se tratara de una venganza por la suerte que permite que estas gentes absolutamente sin gloria surjan en medio de tantos muertos, gesticulen aún, manifiesten permanentemente su rabia, su aflicción o su invencible empecinamiento en vagar sin cesar». ${ }^{26}$ Finalmente, fue el mismo juego del poder el que la sacó del anonimato.

Los líderes pentecostales terminaron negando a esta líder y cofundadora, argumentando una supuesta vergüenza por su condición de mujer y/o un supuesto pasado marcado por el alcoholismo, la prostitución y la miseria. De esta manera, se construyó una imagen abyecta que resumía un ejercicio prohibido para las mujeres y que la hacía merecedora del castigo ejemplar que recibió: ser expulsada (del metodismo), excluida (del movimiento pentecostal), olvidada (del mito fundacional) y recordada como mujer infame (memoria negra). Dentro de una vida marcada por el dolor, la tragedia y el olvido, la familia de Elena fue su único refugio hasta el fin de sus días: «durante el resto de su vida mantuvo contacto estrecho con su hermana y sobrino en Santiago. Se casó, pero no tuvo hijos. Falleció el 10 de diciembre de 1952 en el Hospital Salvador, debido a un absceso pulmonar y un absceso del cerebro. Su sepulcro está en el Cementerio General de Santiago». ${ }^{27}$

\footnotetext{
25 Alberto Rosa, Guglielmo Bellelli y David Bakhurst, ed., «Introducción», en Memoria colectiva e identidad nacional, 19-40 (Madrid: Editorial Biblioteca Nueva, 2000).

26 Foucault, La vida, 82.

27 Inscripción de Defunción del 11 de diciembre de 1952, Registro Civil de Providencia, Inscripción 646-E, Calle Miguel Claro. Florrie Snow, conversación personal, Santiago de Chile, 23 de marzo de 2014.
} 


\section{Una memoria gris. Las otras mujeres del pentecostalismo}

Cuando volvemos la mirada hacia las fuentes originales que relatan los inicios del pentecostalismo, la memoria se ilumina con interesantes testimonios de mujeres que lucharon codo a codo con los hombres por la institucionalización del movimiento. Mostraremos algunos casos concretos y su importancia en los inicios del pentecostalismo, para contribuir así a levantar parcialmente el gris velo que se tejió sobre ellas.

Una de las mujeres más brillantes de esta época fue Laura Ester Contreras, quien escribió sendas cartas (muchas de ellas verdaderas arengas) dirigidas al reciente grupo de pentecostales. Laura formaba parte de la Primera Iglesia de Santiago y fue parte de la Junta de Oficiales, Ecónomos y de la Comisión trimestral que dirigía la iglesia, como secretaria. Según Salazar, «ella fue una intelectual y una teóloga pentecostal». ${ }^{28}$ Es posible que esta etiquetación sea optimista, no obstante, la claridad de sus ideas brindó al naciente movimiento una serie de recursos teológicos para enfrentar el estado intersticial en el cual se encontraba en aquel entonces. En concreto, se conocen ocho escritos apologéticos suyos, que escribió dirigidos al reciente grupo de pentecostales expulsados. En términos generales, en los escritos se aprecian tres principios comunitarios que contribuirán a la reconstrucción de la identidad religiosa pentecostal chilena, los cuales sintetizamos a continuación:

a) Una comunidad de consuelo. En su artículo "Alpha y Omega», Laura Ester destaca que Dios llama a los suyos a no tener miedo y les infunde valor para permanecer firmes ante la adversidad. Luego, alza una oración de consuelo: «Oh, mi señor... te ruego que levantes mi pueblo para que pueda oír tu voz». ${ }^{29}$ De igual forma, en el artículo «No temáis» destaca el valor de Jesús como un ser que otorga consuelo en la soledad y el abandono, poniendo el acento en que Dios finalmente conducirá a los pentecostales «a mayores experiencias del Espíritu santo». ${ }^{30}$ En un tercer artículo, titulado «La anchura del amor del Padre», subraya nuevamente que las personas no deben preocuparse por ser expulsadas de la Iglesia Metodista, más bien deben sentirse contentas de ser perseguidas, como predijera Jesús. Al respecto, se pregunta: «¿cuál es la Iglesia militante de Cristo? ¿Dónde están sus límites?... donde quiera que dos o tres se congregaren en el nombre del Hijo de Dios, allí estará Él en medio de ellos». ${ }^{31}$ Por último, en el artículo denominado «¿Por qué buscáis entre los muertos al que vive?», se dirige fundamentalmente a las mujeres, para recordarles cómo se habrían sentido aquellas que siguieron a Jesús cuando este fue crucificado, y cómo cambió esa situación cuando se enteraron de que había resucitado. ${ }^{32}$ A través de estos recursos discursivos, Laura Ester establece un paralelo entre el mito fundacional del cristianismo y el rito del exilio religioso del naciente pentecostalismo. En concreto, el pentecostalismo se constituía en una comunidad de consuelo para los expulsados, perseguidos y discriminados socialmente. Como los pentecostales habían vivido en carne propia estas penurias, supuestamente podían comprender de mejor forma a los excluidos sociales. Y por lo mismo, no debían esperar a que los marginados llegaran a tocar las puertas del nuevo templo, sino que tenían que ir a buscarlos en las calles y plazas.

(b) Una comunidad carismática. En sus escritos, Laura dio cuenta de un recurrente conflicto entre la tradición representada por la institución eclesial y la innovación representada por el carisma del naciente pentecostalismo. Estos parangones abundan en sus escritos. En el artículo titulado «Ecos de la Conferencia Metodista", se detiene en la importancia de la prédica misionera (una práctica tradicional institucionalizada por el protestantismo), subrayando especialmente que el don de sanidad tendría que ser uno de los recursos más importantes que deberían ser utilizados en este tipo

28 Salazar, «Todas seríamos...», 77.

29 Chile Evangélico [Concepción], 13 de abril de 1910, 2.

30 Chile Evangélico [Concepción], 8 de septiembre de 1910, 19.

31 Chile Evangélico [Concepción], 28 de diciembre de 1909, 1.

32 Chile Evangélico [Concepción], 17 de febrero de 1910, 1-2. 
de prédica. Al respecto, lanza retóricamente el siguiente cuestionamiento: «juzgad vosotros ¿`será bien de nosotros que, por obedecer a nuestros pastores, desechemos el don de Dios? ¡Nunca!». ${ }^{33}$ En otro artículo similar, titulado «La pesca peligrosa», destaca la diferencia que existiría entre el protestantismo y el pentecostalismo en relación a la revelación: «la verdad es necesario vivirla y sentirla para ser comprendida... sólo entonces alguien sabrá dónde tirar su red en el mundo». ${ }^{34}$ En paralelo, Laura Ester comenzó un encendido rechazo a la academia y la intelectualidad, algo que tanto ha pesado al pentecostalismo chileno hasta hoy. Sostenía que «el 99\% de los ministros graduados en las grandes universidades salen a conquistar el mundo para Cristo con sus mentes repletas de conocimientos humanos... pero sin el bautismo de fuego y del Espíritu». ${ }^{35} \mathrm{~A}$ través de proposiciones e imágenes como estas, Laura Ester formó parte de un proceso de construcción de la cultura religiosa del pentecostalismo chileno. Esto le permitió al movimiento diferenciarse no tanto del protestantismo en general, sino más bien de la tradicional prédica misionera que lo caracterizaba, considerada normalmente por el pentecostalismo como intelectualista, fría y descontextualizada. Así, el pentecostalismo apoyó una cultura religiosa cultivada de espaldas a la academia y la intelectualidad, no solo porque dejaba de lado la fe en la razón incentivada por el metodismo, sino también porque llevaba a la religión a la experiencia emocional y testimonial, aunque finalmente cayera de igual forma en la rutinización del carisma.

(c) Una comunidad terapéutica. En «Hojas de sanidad para las naciones», Laura Ester insiste en el valor de la sanidad como recurso clave para llegar al pueblo chileno, afirmando que "Jesús vino a dar libertad a los cautivos y sanidad a su pueblo", para luego preguntarse: "¿Acaso nosotros no tenemos quién cure nuestras llagas y quién tenga compasión de nuestras dolencias?». ${ }^{36}$ En otra carta dirigida «A los jóvenes evangélicos», considerados por ella como «las primicias de esta tierra», "vasos elegidos por el Altísimo», «antorchas de la verdad», «fundidos con el Espíritu», ${ }^{37}$ los incentiva a liderar el proceso de institucionalización del pentecostalismo y a constituir un nacionalismo religioso, pues la salud espiritual de Chile dependería de ellos: "Vosotros sois responsables de la vida espiritual de esta nación». ${ }^{38}$ De esta forma, y a través de diferentes vías, esta pensadora contribuyó a esculpir uno de los pilares más distintivos de la cultura pentecostal: la oferta de sanidad, en tiempos en los que los pobres y excluidos no tenían acceso al sistema formal de salud.

Pero la memoria no solo está construida por mujeres especialmente significativas y que brillan intelectualmente. También hay una pléyade de mujeres que colaboraron en la construcción de múltiples dimensiones de este naciente pentecostalismo, como veremos a continuación.

Una vez establecidas las primeras congregaciones pentecostales, el rol de las mujeres como profetizas y predicadoras fue muy importante. Incluso en Valparaíso y Santiago, donde fueron mayormente silenciadas por la administración de Hoover, su rol de predicadoras de la calle siguió activo. Su papel fue especialmente relevante en el centro y sur del país, concretamente en Concepción y Temuco: «las hermanas se trasladaron en el tren a Chiguayante (Concepción) para la obra del Señor, las cuatro hermanas siguientes, además de la esposa del pastor: Isabel Fernández de Núñez; Juana viuda de González; Rosa Fontena de Sepúlveda; Noemí de Kopmann». ${ }^{39}$ También se describen algunas de las actividades concretas que realizaban: «el lunes tuvimos el gozo de ver dirigir la reunión a la hermana Auristela Oliviera, a quien oímos con agrado y edificación, porque lo que necesitamos ahora son testimonios sinceros y de tal naturaleza que nos constriñan a una vida

33 Chile Evangélico [Concepción], 3 de marzo de 1910, 1-2. 34 Chile Evangélico [Concepción], 5 de mayo de 1910, 1-2.

36 Chile Evangélico [Concepción], 19 de mayo de 1910, 2. 37 Chile Evangélico [Concepción], 26 de diciembre de 1910, 3. 38 Chile Evangélico [Concepción], 26 de noviembre de 1909, 3. 39 Chile Evangélico [Concepción], 13 de noviembre de 1909, 3. 
mejor». ${ }^{40}$ De alguna u otra manera, las mujeres instan a otras mujeres a predicar, como se aprecia en una carta enviada por Noemí de Kopmann a la revista Chile Evangélico:

Carta a las hermanas de Chiguayante. Estamos orando por ustedes, pidiendo que unidas se levanten, que prediquen con sus vidas y con sus obras, que muestren al mundo que las rodea, que son hijas de Dios... levantémonos unidas para alistarnos en las filas de los valientes, de los esforzados, y alcanzaremos la victoria mediante la ayuda del poder de lo alto. E1 nombre de nuestro Dios será glorificado, y muchas almas salvadas de la muerte eterna. ${ }^{41}$

En estas actividades es interesante apreciar la participación de mujeres jóvenes:

$[\mathrm{P}]$ or algunos días hemos tenido entre nosotros a la joven hermana Julia Hernández de la Iglesia Pentecostal de Gorbea (Araucanía) que ha venido a nuestra iglesia con un mensaje de Dios que nos fue dado en la reunión del lunes 1 de mayo y tenemos que glorificar el nombre de nuestro bendito Padre porque no necesita la confección de largos sermones para sus mensajes. ${ }^{42}$

Diferenciándose del protestantismo misionero, el naciente pentecostalismo resaltó la entrega de un mensaje espontáneo y emocional. En este escenario, una de las jóvenes más particulares fue Remigia Arancibia, hija de pastores de Concepción y Chiguayante (Ceferino Arancibia y Natalia M. de Arancibia). En una carta enviada a sus padres el 9 de diciembre de 1910, escribió:

[E]1 jueves pasado el Señor me mandó donde el hermano F... yo tenía mensaje del Señor... una hermana vio en visión que los enfermos, cojos en sillas, ciegos, tuertos, etc. eran sanados en nombre de Jesús de $\mathrm{Na}-$ zareno y se levantaban glorificando a Dios... reciban todo el cariño de su hija que los ama. ${ }^{43}$

Así, las mujeres profetizan, ven visiones e imponen manos, $y$ dan forma al tema principal del discurso pentecostal: la sanidad, constituyendo al pentecostalismo en una comunidad

40 Chile Evangélico [Concepción], 31 de diciembre de 1909, 3.

41 Chile Evangélico [Concepción], 29 de octubre de 1909, 1-2.

42 Chile Pentecostal [Concepción], 15 de mayo de 1911, 7.

43 Chile Pentecostal [Concepción], 18 de diciembre de 1910, 5. terapéutica por excelencia, como promulgaba Laura Ester.

En una carta sobre el viaje misionero realizado por Natalia M. de Arancibia y Rosa E. de Pino, se relata lo siguiente:

[L]a invitación vino de la Iglesia de Río Bueno, salimos el día 27 de diciembre, alcanzando hasta $\mathrm{Pi}$ trufquén, donde asistimos a una reunión dirigida por el pastor de esa Iglesia. Al otro día llegamos a Río Bueno acompañadas del Pastor Campos y nos esperaban en Gorbea. El 4 de enero nos dirigimos a Río Bueno. Esa noche nos despedimos para ir a la Unión. En esa noche tuvimos una buena asistencia y pudimos exclamar: «Señor, la mies es mucha, son pocos los obreros, levanta misioneros en esta tu nación». El día 6 salimos para Gorbea, La Faja y Pitrufquén, en cuyas iglesias dimos nuestros testimonios con la experiencia del bautismo del Espíritu Santo... el jueves 11 nos dirigimos a Temuco para visitar la nueva obra que se ha abierto en ese pueblo a cargo de nuestro hermano José Flores... el día 15 seguimos a Mulchén donde alcanzamos a celebrar algunas reuniones donde están los hermanos García y su esposa. El día 17 salimos en dirección a nuestras casas. ${ }^{44}$

Aquí se muestra la disposición que tenían los pastores de Concepción y Temuco, quienes dieron amplia libertad a las mujeres para predicar, ser misioneras y profetizar; ello permitió trasmitir una memoria alternativa a la oficial. En contrapartida, los pastores del centro del país (Santiago y Valparaíso) se preocupaban por elaborar una memoria dorada sobre los hombres y nubosa sobre las mujeres.

Natalia de Arancibia (esposa de Ceferino Arancibia) también dio sus testimonios a través de la revista Chile Pentecostal. Entre los diversos aspectos planteados, describe al pentecostalismo como una religión de los pobres: «Dios está obrando... en los viles y miserables, en aquellos de los cuales hablaba Pablo, ser como basura, ser la hez del mundo, pero imitadores de Dios como hijos amados». ${ }^{45} \mathrm{El}$ espíritu pentecostal parecía llamado a representar al espíritu de sus líderes mujeres, personas no reconocidas y olvidadas. Así, los inmigrantes pobres, huérfanos, alcohólicos, mujeres, viudas, prostitutas, etc. son llamados a formar parte de las comunidades pentecostales. Estas mujeres iban a buscar

44 Chile Pentecostal [Concepción], 15 de marzo de 1912, 3-5. 45 Chile Pentecostal [Concepción], 18 de diciembre de 1910, 2-3. 
a los desheredados a las calles. Muchos de ellos vivían en la casa pastoral, atendidos por la esposa del pastor o la pastora. Sin embargo, el rol femenino fue constituyéndose poco a poco en un rol tradicional materno, ajeno al papel intelectual masculino. Esto se aprecia en un documento publicado titulado «Carta abierta»:

$[\mathrm{M}] \mathrm{i}$ amada hermana... Las cosas que son del cielo son el amor y la caridad que permanecen para siempre. ¡Llénanos Señor estas cosas porque ellas producen la bondad! La piedad nos enseña a ser amparo del caminante, guarda de la viuda, vestir el huérfano, dar pan al hambriento $y$, armado de estas cosas... tendrás un cuerpo y un vestido muy precioso y serás codiciada de naciones, porque te has vestido con los vestidos del cielo, de reliquias eternas... como la madre que reparte pan a sus hijos y que da el alimento de sus entrañas para alimentar y no lo de otro, sino lo propio. ${ }^{46}$

En uno de los informes enviados a la revista $C h i-$ le Pentecostal, se destaca que:

[E]ste crecimiento es debido particularmente a la predicación que se principió hacer en los conventillos por varias hermanas que se prestaron voluntariamente para salir después de la Escuela Dominical a dar sus testimonios en público. El primer día que salieron estas "palomas mensajeras» se convirtieron cuatro personas. ${ }^{47}$

La aparición de la imagen del columbograma evidencia una dimensión significativa de la mujer pentecostal: se trata de una mensajera, aquella que realiza el trabajo de traer las almas a las iglesias para que el pastor (hombre) las gobierne. Así, algo que parece una suerte de elogio que engrandece al trabajo de la mujer, evidencia una historia de empequeñecimiento e invisibilización del trabajo femenino.

Las mujeres también recorrían las iglesias recolectando dinero para mantener el funcionamiento de la revista Chile Pentecostal:

Tenemos de regreso a nuestra hermana Rosa $\mathrm{E}$ de Pino, después de una gira de 18 días por la Frontera... para adquirir una imprenta propia para la publicación regular de la Revista... mientras que nuestra hermana Remigia Arancibia viaja con la misma finalidad... ${ }^{48}$

46 Chile Pentecostal [Concepción], 15 de julio de 1912, 3-4. 47 Chile Pentecostal [Concepción], 15 de noviembre de 1914, 6. 48 Chile Pentecostal [Concepción], 1 de abril de 1913, 2.
Esto se aprecia en otro testimonio que procede del denominado Norte Chico de Chile, concretamente de Fragüita (Región de Atacama). E1 14 de abril de 1910, Mercedes Campusano de Guardia escribió lo siguiente:

[C]on mucho gusto haré propaganda de Chile Pentecostal en el nombre de mi Padre. Soy una débil mujer, pero sé que para Dios no hay diferencia. Estamos orando para que venga un pastor. Aquí hay mucha semilla sembrada, próxima a brotar, falta solamente un pastor. ${ }^{49}$

Podemos apreciar cómo mientras las mujeres predicaban y servían de misioneras en las pequeñas iglesias, simultáneamente se institucionalizaba la necesidad de un pastor hombre que dirigiera la iglesia. Esto se aprecia en otros testimonios de Clara Luz de B. de López, de Petorca (Valparaíso). Esta mujer predicaba, pero consideraba su rol como pasajero y supletorio, a la espera de que un hombre lo desarrollase.

Hermanos antes había un hermano a cargo de la obra del Señor, que estaba atendiendo a las predicaciones por más de un año pero ya no sigue más y por esto estamos sin predicador local... pero a pesar el Señor ha obrado maravillas en estos últimos días, muy especialmente en la sanidad. ${ }^{50}$

Así, en general, la memoria del liderazgo pentecostal se iba constituyendo en una conmemoración del sufrimiento que apelaba a lo sensible. Pero, según Candau, «la defensa de la identidad y el sentimiento de pertenencia exigen ese peso de lo trágico sentido y transmitido». ${ }^{51}$

\section{El rol de la mujer o la cordura como control}

Como señalábamos anteriormente, a medida que el naciente pentecostalismo se fue institucionalizando, el rol de las mujeres dentro del movimiento se tornó problemático y se fueron desarrollando estrategias para controlarlas y evitar la reaparición de liderazgos revolucionaros (como el de Elena). En este contexto, se impulsó la sumisión del accionar femenino bajo la figura del pastorado masculino. ¿Cuál

\footnotetext{
49 Chile Pentecostal [Concepción], 15 de mayo de 1911, 5. 50 Chile Pentecostal [Concepción], 15 de noviembre de 1914, 8.
} 51 Candau, Memoria e identidad, 148. 
fue la táctica esgrimida?: no dejar que los cultos estimulasen los vigores del espíritu humano y concluyeran en desorden. Esto permitiría finalmente volver a la cordura. En otras palabras, volver a la cordura era el disfraz que se levantaba para que las mujeres retornaran a su rol tradicional de sumisión.

El pentecostalismo se preguntó concretamente en uno de sus escritos: «¿Cuál es el ministerio de la Mujer?» La pregunta fue respondida al tenor de un artículo publicado en una revista pentecostal norteamericana, titulado suspicazmente «The Trust». En el artículo se defiende el rol de la mujer como profetiza, predicadora y maestra, sin importar su estatus (soltera, casada, joven, adulta, etc.). Para defender el liderazgo administrativo-pastoral de la mujer, se recurrió a la memoria bíblica: «aún en el Antiguo Testamento unas mujeres tituladas profetisas y solamente por nombres comprendemos que tomaban parte públicamente de la obra del Señor. Unas guiaban, otras enseñaban y otras juzgaban el pueblo». ${ }^{52}$

Estas actividades podrían realizarlas al igual y a la par que los hombres:

$[\mathrm{V}]$ emos que una mujer es puesta al mismo lado con el hombre a anunciar el mensaje de Dios. Si una mujer lo podía hacer antes, creemos que lo puede hacer hoy día también [...] nos parece que las mujeres de hoy día a quienes Dios ha llamado tienen el mismo derecho de instruir y enseñar La Biblia. ${ }^{53}$

No obstante, estos mensajes acaban sembrando ambigüedad y no pasan de ser buenas intenciones, pues jamás se habla concretamente de la posibilidad de predicar desde el púlpito de la iglesia, ni tampoco de la posibilidad de convertirse en pastoras como sus compañeros varones.

Siguiendo la senda del cuestionamiento, el pentecostalismo se preguntó específicamente por el rol que le cabía a la mujer dentro del trabajo misionero. Esta vez se utilizó como referencia al The Apostolic Faith para construir la respuesta, concretamente un artículo intitulado «Las

52 Chile Pentecostal [Concepción], 6 de abril de 1911, 5-6. 53 Chile Pentecostal [Concepción], 6 de abril de 1911, 5-6. mujeres». En él, la pregunta era respondida de la siguiente manera:

¿Son llamadas las mujeres a predicar el evangelio? En Cristo Jesús no hay macho ni hembra, porque todos vosotros son uno en Cristo. El Espíritu Santo profetiza y predica por una y otra persona... pero la Biblia no impide a la mujer dar testimonio ni profetizar en la iglesia. ${ }^{54}$

Sin embargo, una vez más las mujeres no pueden predicar desde el púlpito, ni tampoco ser líderes pastorales. Solo se les permitió predicar en las calles, en los hogares y posteriormente en hospitales y cárceles, pero no en las iglesias. Así, se excluyó a las mujeres de los dos roles más importantes dentro del pentecostalismo.

En el artículo titulado «La mujer cristiana» ya se manifiesta de manera muy clara el control y la vigilancia que se ejercía sobre los cuerpos femeninos:

[C] uando miro a la mujer cristiana llevando colgado de sus orejas unas joyas de distintos nombres. Haciendo una incisión en la oreja, que Dios no hizo, me da pena, profunda pena este hecho criminoso de romper la carne a una pobre guagüita para colgarle algo de lo cual no puede agradarse el Señor. ${ }^{55}$

La cultura pentecostal también influyó en las mujeres del protestantismo histórico. Especialmente en la Iglesia Alianza Cristiana y Misionera, que en ese entonces estaba bajo la dirección del pastor Weiss: «la hermana María Preisler, de la iglesia de Valdivia... ha logrado interesar mucho a algunas jovencitas alemanas $\mathrm{y}$ asiste con frecuencia a nuestros cultos». ${ }^{56} \mathrm{De}$ hecho, en el caso del protestantismo misionero, se tendía a considerar que el bautismo del Espíritu Santo era una experiencia de mujeres. En una carta escrita por el misionero noruego Maggie Gilchrist desde Huillinco (Isla de Chiloé), indicó que recibió el bautismo del Espíritu Santo de la mano de dos hermanas venidas de Valparaíso (Elena Laidlaw y $\mathrm{Na}-$ talia de Arancibia), testimoniando lo siguiente: «cuando estoy bajo este poder maravilloso, todo mi cuerpo tiembla y muchas veces pierdo

54 Chile Pentecostal [Concepción], 15 de junio de 1912, 2-3. 55 Chile Pentecostal [Concepción], 24 de noviembre de 1910, 5. 56 Chile Evangélico [Concepción], 12 de noviembre de 1909, 3. 
las facultades para hablar, solamente puedo hacer unos sonidos peculiares». ${ }^{57}$

De igual forma, su hermano Neil Gilchrist envió otra carta relatando que:

$[\mathrm{H}]$ ay cuatro hermanas que han recibido el bautismo del Espíritu y hablan y cantan en lenguas extrañas, como el Espíritu les da que hablen y cuando están en oración tiemblan y son sacudidas de una manera tan fuerte que tiembla toda la capilla, como si fuera un terremoto, y estas manifestaciones no suceden de vez en cuando, sino diariamente. ${ }^{58}$

El mismo encargado de la obra, N.O. Gunstad, agregó lo siguiente:

[L]a visita de las hermanas de Valparaíso a la Isla de Chiloé, no fue en vano... en el culto de la noche mi esposa habló en lenguas desconocidas tres veces; y dos más de las hermanas cayeron bajo el poder del Espíritu los chilenos que no tenían interés en nuestra obra ahora vienen a nuestras reuniones y parecen hambrientos de la verdad. ${ }^{59}$

Pese al avivamiento y la conversión de nuevas almas, los problemas que el bautismo del Espíritu Santo generó al interior de la Alianza Misionera manifestaban nuevamente el dilema entre tradición y carisma. Al respecto, Oyarzún destaca que: «durante el pastorado de Gunstad la Iglesia de Huillinco se separó de la Misión por causa de doctrinas antagónicas a la común fe de la Misión, quedando independiente con este pastor, quien introdujo esas doctrinas». ${ }^{60}$

A pesar de esos conflictos, los misioneros noruegos estrecharán sus relaciones con los pentecostales y seguirán enviando escritos a la revista. Marie Gunstad y Kirsti Melbostad, por ejemplo, escribieron desde Huillinco Ancud (Chiloé). ${ }^{61}$ Además de confraternizar, los misioneros noruegos Neil Gunstad y María Gunstad visitaban y predicaban para el naciente movimiento pentecostal en Concepción, Lautaro y Mulchén. ${ }^{62} \mathrm{Si}$ bien surgieron

57 Chile Evangélico [Concepción], 11 de septiembre de 1910, 15. 58 Chile Evangélico [Concepción], 11 de septiembre de 1910, 6. 59 Chile Evangélico [Concepción], 11 de septiembre de 1910, 15. 60 Arturo Oyarzún, Reminiscencia histórica de la Obra Evangélica en Chile (Valdivia: Imprenta Alianza, 1921), 68.

61 Chile Pentecostal [Concepción], 15 de mayo de 1914, 7-8.

62 Chile Pentecostal [Concepción], 15 de febrero de 1915, 6. conflictos en Chiloé, Río Bueno y Valdivia, la Alianza Cristiana siguió manteniendo relaciones fraternales con los pastores. Esto se observa en una carta que envió María B. de Rudolph, afirmando que:

[F]ue una bendición tan grande que se levantaban las almas alabando al Señor en lenguas extrañas como el Espíritu les daba que hablasen fue una maravilla tan grande como nunca había visto... grande es el gozo que siente nuestra alma, cuando el Señor nos visita con su Santo Espíritu. ${ }^{63}$

\section{Retazos de memoria: la lucha contra la amnesia}

Pese a la negativa comandada por líderes masculinos que buscaba desvalorizar, ocultar o simplemente difamar el papel que jugaron las mujeres en la fundación del movimiento pentecostal chileno, también debemos destacar la existencia de algunos líderes que intentaron reconocer el estatus igualitario del trabajo religioso de la mujer e incorporarlas en el mito fundacional institucional del movimiento. Si bien estas estrategias terminaron siendo simples bocanadas de memoria que «solo pueden expandirse en el tejido de las imágenes y del lenguaje», ${ }^{64}$ es importante señalarlas y destacarlas, pues no solo nos permiten obtener una idea más acabada del rol de las mujeres en este movimiento, sino que también nos muestran otras apreciaciones existentes sobre su rol, existentes dentro de la misma organización, lo que finalmente contribuye a reconstruir esta memoria oculta del pentecostalismo chileno.

En primer lugar, debemos destacar que los líderes pentecostales que apoyaron la participación de las mujeres en el movimiento (sea porque sus esposas eran líderes o simplemente porque entendían el liderazgo como una habilidad provista por el Espíritu Santo sin importar el género), estaban alejados del centro geográfico que dirigía el movimiento (Santiago y Valparaíso), lo que limitaba cualquier

\footnotetext{
63 Chile Pentecostal [Concepción], 15 de noviembre de 1914, 7. 64 Joel Candau, Antropología de la Antropología (Buenos Aires: Edi-
} ciones Nueva Visión, 2002), 66. 
influencia o impacto de sus medidas. Además, varios de ellos fallecieron tempranamente, lo que limitó la promulgación de sus ideas dentro de su entorno. Tal fue el caso del pastor Ceferino Arancibia, su esposa Mercedes e hija Remigia, todos connotados líderes del movimiento. En diciembre de 1910, el pastor Ceferino fue enviado por Hoover desde Valparaíso a la iglesia de Concepción. El grupo de Concepción era liderado por Tulio Morán y estaba conformado por personas que se habían escindido de la Iglesia Presbiteriana. Arancibia organizó oficialmente esta nueva iglesia pentecostal en junio de 1911, pero debió retornar junto a su esposa a Valparaíso por su enfermedad, falleciendo el 27 de enero de $1914 .{ }^{65}$ Sin embargo, su hija Remigia continuó como misionera nacional del movimiento, pese a que este rol ya estaba subyugado al papel del pastor. Por su parte, el pastor José Flores, también procedente de la iglesia de Valparaíso, fue enviado a Temuco para dar comienzo a la obra en 1912, pero murió en 1913 por su enfermedad.

Ambas iglesias fueron muy activas y permitieron a las mujeres ejercer su liderazgo, abriendo los púlpitos para que predicaran, profetizaran o entregaran sus testimonios, además de permitir que predicaran y tuvieran rol de misioneras en las calles de la ciudad. Así, varias mujeres situadas en los márgenes geográficos y sociales del pentecostalismo se hicieron de un nombre y se abrieron un espacio en la posteridad, con la esperanza de no desaparecer en el olvido, no por ellas mismas, sino por el rol que debían asumir como mujeres en el movimiento pentecostal.

También debemos destacar la importancia que tuvieron los líderes y editores de las revistas Chile Evangélico y Chile Pentecostal. Por un lado, Tulio Morán, director de Chile Evangélico, no solo abrió las puertas al movimiento pentecostal y le dio espacio en la revista, sino que también defendió a la hermana Elena. Morán se dedicó a publicar y rebatir todas las difamaciones de Elena que hacían los otros periódicos de la época, como El Heraldo Evangélico (de la Iglesia Presbiteriana), el Cristiano (Iglesia Metodista) o El Mercurio (diario secular). Tulio Morán fue incluso abogado de la hermana Elena, difundió su trabajo y solicitó la apertura de las otras iglesias al trabajo de Elena. De hecho, Chile Evangélico le dedicó su portada en el n. ${ }^{\circ}$ 45: «Reverendo Tulio Rojas, Fundador de Chile Evangélico el 11 de septiembre de 1909»; justo un día antes de la expulsión, separación y nacimiento del movimiento pentecostal. $\mathrm{Al}$ respecto se dice de $\mathrm{Tu}-$ lio Rojas «comenzó el Chile Evangélico bajo la premisa de Juan Wesley: “emprended grandes obras por el Señor, esperad grandes cosas del Señor"». ${ }^{66}$ Chile Evangélico se publicará solo durante 14 meses. Sin embargo, una vez que el movimiento pentecostal logró transformarse en iglesia (1910), la revista cambió de nombre a Chile Pentecostal y automáticamente eliminó toda referencia a la hermana Elena, desconociéndose hasta hoy las razones de este hecho. Así, y de manera paradójica, pareciera que Elena y otras mujeres se hicieron de un nombre que les ha permitido abrirse en la posteridad y no desaparecer en el olvido.

Por otro lado, tenemos la publicación de Chile Pentecostal, la cual comenzó el 24 de noviembre de 1910, bajo la dirección de Enrique Koppman. Si bien el periódico no hacía referencia a la hermana Elena, Koppman se destacó por abrir las puertas a todas las mujeres, no solo las pentecostales, sino también a todas aquellas, tanto de Chile como del extranjero, que quisieran publicar en el periódico. En esta línea, publicaron distintas cartas y artículos provenientes de Ecuador, Argentina y Brasil. Lamentablemente, por problemas económicos se dejó de publicar en el año 1915.

Finalmente, dentro del protestantismo misionero, uno de los personajes más abiertos al movimiento pentecostal fue el pastor H.L. Weiss. Él había llegado a Valdivia en el año 1899, pero murió relativamente joven, a los 48 años de edad (probablemente por el duro clima del sur de Chile). E1 pastor Weiss escribió

65 Rasmussen y Helland, La Iglesia Metodista, 24.

66 Chile Evangélico [Concepción], septiembre de 1910, 6. 
algunas cartas en Chile Evangélico. En una de ellas relató que recibió en su iglesia la visita de Elena y Mercedes: «Dios mandó a dos humildes hermanas (Natalia y Elena) desde Valparaíso para que nos comunicasen y fuésemos también recipientes de las grandes bendiciones que los hermanos de Valparaíso y Santiago estaban gozando». ${ }^{67}$

A continuación, resaltó un aspecto especialmente significativo: "Hasta los pastores se humillaron hasta el polvo de la tierra. Los pastores son los primeros que resisten al Espíritu Santo y los últimos que se humillan en el polvo de la tierra», ${ }^{68}$ enfatizando que son ellos los que resisten el liderazgo femenino y el impulso carismático. E1 pastor Weiss autorizó también a otras mujeres pentecostales para que visitasen sus iglesias, para que dieran sus testimonios, profetizaran e impusieran sus manos en aras de recibir el bautismo del Espíritu Santo.

Pese a los riesgos de que se produjera un cisma o separación ante la presencia de las mujeres pentecostales en el seno de estas iglesias, estos hechos no fueron de mucho impacto. ${ }^{69}$ Solo se conocieron dos casos. En Valdivia, «un grupo de veinte personas abandonan la Iglesia Alianza Cristiana y Misionera, para unirse el pastor Carlos del Campo", ${ }^{70}$ pero no se unieron a Hoover, sino que formaron un grupo independiente conocido como Iglesia del Señor, en diciembre de 1911. En Huillinco (Chiloé) también se escindió un segundo grupo, pero muy pequeño. Pese a ello, el pastor Weiss fue respetuoso y tolerante con el movimiento pentecostal, especialmente con las mujeres que lideraban el movimiento. Tanto era el aprecio y admiración que los pentecostales sentían por él, que las iglesias de Santiago llamaron al Pastor Weiss, antes que a Hoover, para que se hiciera cargo del movimiento pentecostal. Al

67 Chile Evangélico [Concepción], 10 de diciembre de 1909, 2. 68 Chile Evangélico [Concepción], 10 de diciembre de 1909, 2. 69 El cisma mayor se produjo años antes (1908), cuando el misionero Mac Donald se separó de la Alianza para unirse a la Misión Bautista, que hasta entonces no tenía iglesias en Chile. Esto sucedió en Temuco y el mencionado misionero se llevó 300 miembros y dos pastores chilenos. Oyarzún, Reminiscencia histórica, 71.

70 Luis Orellana, El Fuego y la Nieve. Historia del Movimiento Pentecostal en Chile 1909-1932 (Concepción: CEEP, 2006), 38. parecer, por respeto y consideración a la Iglesia Metodista Episcopal, Weiss no aceptó. Sin embargo, siguió estableciendo comunicación con los pentecostales, al tiempo que evitó que sus iglesias se separaran y se unieran indefinidamente al movimiento pentecostal, como hasta entonces estaba sucediendo con la Iglesia Metodista. ${ }^{71}$

\section{Consideraciones finales}

Hemos mostrado que la memoria colectiva sobre los orígenes del pentecostalismo chileno se organiza en torno a la construcción de una imagen infame de Elena (memoria negra), así como de las otras mujeres que participaron en el proceso (memoria gris). Una vez significado su liderazgo como hereje solo por su condición de mujer, se fueron desarrollando y consolidando estrategias para controlar la feminidad y evitar la reaparición de liderazgos revolucionarios.

E1 control de los cuerpos procuró contener los vigores del espíritu humano que amenazaban con desbordarse en la experiencia bautismal. Las mujeres fueron prescritas a predicar en el espacio abierto de las calles, en la intimidad de los hogares, en los hospitales y cárceles, a la vez que se les prohibía hacerlo en las iglesias, marginándolas de los púlpitos. Progresivamente se fue estableciendo la sumisión del accionar femenino bajo la figura del pastorado masculino. Por supuesto, esto no fue un proceso monolítico y homogéneo, pero el poder sí se cuidó de mantener las fuentes de su cuestionamiento lejos de los centros geográficos del poder.

Lo que es claro luego de nuestro recorrido es el rol que la producción de la memoria negra y la memoria gris ha tenido en la construcción del mito fundacional del pentecostalismo chileno, el cual funciona como fundamento de la reproducción de las prácticas sociales de marginación y del control de la femineidad en

\footnotetext{
71 La Iglesia Metodista se debilitó mucho con el naciente movimiento Pentecostal. En el año 1911, otros cinco pastores y sus congregaciones abandonaron la Iglesia Metodista, y en el año 1913 una sexta iglesia metodista de Santiago se pasó a los pentecostales. Rasmussen y Helland, La Iglesia Metodista, 19.
} 
sus intentos por acceder al espacio prohibido del liderazgo pentecostal. Así, el ejercicio de analizar la producción histórica del olvido de Elena y otras mujeres claves en la historia fundacional del pentecostalismo chileno, nos ha llevado a apreciar el carácter instrumental de la memoria colectiva esculpida por el pentecostalismo.

\section{Bibliografía}

\section{Fuentes primarias}

Chile Evangélico [Concepción], 1909-1910.

Chile Pentecostal [Concepción], 1910-1915.

El Mercurio [Santiago], 14 de septiembre de 1909.

Fuego de Pentecostés [Santiago], mayo de 1933.

Snow, Florrie. Conversación personal. Santiago de Chile, 23 de marzo de 2014.

\section{Fuentes secundarias}

Bullon, Dorothy. Hacia una teología de Avivamiento. Barcelona: CLIE, 1998.

Burgess, Stanley y Eduard Van der Mass. Intenational Dictionary of Pentecostal Charismatic Movements. Michigan: Zondervan, 2003.

Candau, Joel. Antropología de la Antropología. Buenos Aires: Ediciones Nueva Visión, 2002.

Candau, Joel. Memoria e identidad. Buenos Aires: Ediciones del Sol, 2001.

Freire, Gedeón. Matriz Pentecostal Brasileira. Asambleias de Deus. 1911-2011. Río de Janeiro: Diálogos, 2013.

Foucault. Michel. La vida de los hombres infames. La Plata: Altamira, 1996.
Hoover, Mario. 2002. El movimiento Pentecostal en Chile del siglo XX. Santiago: Eben Ezer.

Kessler, Juan. A study of the older Protestant missions and churches in Peru and Chile. With special reference to the problems of division, nationalism and native ministry. Goes: Oosterbaan \& le Cointre N.V., 1967.

Lavabre, Marie Claire. «Sociología de la memoria y acontecimientos traumáticos». En Guerra civil. Mito y memoria, editado por Julio Aróstegui y François Godicheau, 31-55. Madrid: Marcial Pons, 2006.

Le Goff, Jacques. Enciclopédia Einaudi. Vol. I, Memória e História. Madrid: Imprenta Nacional - Casa da Moneda, 1991.

Mansilla, Miguel Ángel y Luis Orellana Urtubia. «Haciendo memoria de líderes religiosas olvidadas: el reconocimiento póstumo del trabajo de las pastoras en el pentecostalismo chileno». Sociedad y religión 23, n. 40 (2013): 77-130.

Mansilla, Miguel y Luis Orellana. «Las pastoras pentecostales: metáforas sobre el liderazgo femenino en la Iglesia Evangélica Pentecostal (1972-2001)». Memoria y Sociedad, n. 36 (2014): 83-98.

Orellana, Luis. El Fuego y la Nieve. Historia del Movimiento Pentecostal en Chile 1909-1932. Concepción: CEEP, 2006.

Oyarzún, Arturo. Reminiscencia bistórica de la Obra Evangélica en Chile. Valdivia: Imprenta Alianza, 1921.

Pennebaker, James y Michael Crow. «Memorias colectivas: la evolución y la durabilidad de la historia». En Memoria colectiva e identidad nacional, editado por Alberto Rosa, Guglielmo Bellelli y David Bakhurst. Madrid: Editorial Biblioteca Nueva, 2000. 
Rasmussen Schick, Alice y Dean Helland Talbert. La Iglesia Metodista Pentecostal, ayer y boy, tomo II. Santiago: Plan Mundial de Asistencia Misionera en Chile, 1987.

Rosa, Alberto, Guglielmo Bellelli y David Bakhurst, ed. «Introducción». En Memoria colectiva e identidad nacional, 19-40. Madrid: Editorial Biblioteca Nueva, 2000.

Salazar, Elizabeth. «Todas seríamos rainhas. História do pentecostalismo chileno na perspectiva da mulher 1909-1935». Dissertação de Maestrado em Ciencias da Religião, UMESP, 1995.

Sepúlveda, Juan. De peregrinos a ciudadanos. Breve historia del cristianismo evangélico en Chile. Santiago: Fundación Konrad Adenauer, 1999.

Tarducci, Mónica. «Estudios feministas de religión: una mirada muy parcial». Cuadernos Pagu Universidad de Campinas, n. 16 (2005): 97-114.
Vergara, Ignacio. El Protestantismo en Chile. Santiago: Ed. del Pacífico, 1962.

Recibido: 14 de junio de 2016

- Aceptado: 22 de mayo de 2017

- Disponible en línea: 30 de junio de 2018

\section{Cómo citar este artículo}

Mansilla, Miguel Ángel, Wilson Enrique Muñoz Henríquez y Carlos Daniel Piñones Rivera. «Memoria de un olvido. La exclusión de mujeres de la memoria fundacional del pentecostalismo chileno (1909-1915)». Memoria y Sociedad 22, n. 44 (2018): 102-117. https://doi.org/10.11144/Javeriana.mys22-44.moem 